\title{
Export Restraints in a Model of Trade with Capital Accumulation ${ }^{1}$
}

\author{
Giacomo Calzolari ${ }^{\#}$ - Luca Lambertini ${ }^{\S}$ \\ \# Dipartimento di Scienze Economiche \\ Università degli Studi di Bologna \\ Piazza Scaravilli 2 \\ 40126 Bologna, Italy \\ calzolari@economia.unibo.it \\ $\S$ Dipartimento di Scienze Economiche \\ Università degli Studi di Bologna \\ Strada Maggiore 45 \\ 40125 Bologna, Italy \\ fax: +39-051-2092664 \\ lamberti@spbo.unibo.it
}

\footnotetext{
${ }^{1}$ We thank Ennio Cavazzuti and Roberto Cellini for helpful suggestions. The usual disclaimer applies.
} 


\begin{abstract}
This paper examines the impact of voluntary export restraints (VERs) in an international duopoly modelled as a differential game. We employ two well known capital accumulation dynamics for firms, due to Nerlove and Arrow and to Ramsey, respectively. First we investigate Cournot behaviour, showing that, in both models, a VERs cannot be 'voluntarily' employed by the foreign firm. Our analysis therefore suggests that the empirical observation of VERs corresponds to their use either as coordinating or as quasi-collusive devices in markets where firms are price setters and sales are not capacityconstrained. This is confirmed by our analysis of price competition. The Bertrand steady state of the Solow-Nerlove-Arrow model coincides with the Cournot equilibrium, and therefore the foreign firm cannot be expected to voluntarily adopt an export restraint. However, the opposite holds in the case of price behaviour in the Ramsey setting, where the adoption of an export restraint may increase the profits of both firms.
\end{abstract}

JEL Classification: D43, D92, F12, F13, L13

Keywords: intra-industry trade, trade policy, differential games, capital accumulation 


\section{Introduction}

Strategic trade policy literature is, with few exceptions, essentially based on a static framework (see Brander 1995). Nevertheless, long-term interactions characterizing international oligopolistic markets are at odds with the oneshot static games generally employed. ${ }^{1}$

Voluntary export restraints (VERs) are often considered as coordinating or quasi-collusive devices (see, e.g., Berry, Levinsohn and Pakes, 1999). Indeed, most of the existing theoretical literature justifies this view only insofar as firms are price setters.

Harris (1985) first analyzed VERs in a static duopoly model. He showed that when firms compete à la Bertrand on differentiated products, then a VER at the free trade level of imports increases profits of both domestic and foreign firms. This result is consistent with what has been found by Mai and Hwang (1988) in a more general analysis based on a conjectural variation static approach. However, this paper shows that with Cournot competition VER is ineffective but in more collusive settings (i.e. those with positive quantity conjectures) it hurts the foreign firm and fails to be a 'voluntary' strategic trade policy. In general, the consequences of quantity restrictions are known to depend on whether imports are strategic and/or demand substitutes or complements for domestic products. This, in turn, depends on whether market interaction takes place in outputs or prices. When firms set quantities (prices) and goods are demand substitutes (complements), output restrictions impede the ability of the foreign firm to compete in the domestic market, thereby acting to facilitate collusion and raise prices and profits (see Krishna, 1989). ${ }^{2}$

This view is reinforced by Suzumura and Ishikawa (1997), who explore the implications of a voluntary export restraint agreement on profits and welfare in a duopoly model with product differentiation and conjectural variations. They assume that the imposition of a VER makes the domestic firm into a Stackelberg leader, and show that a VER introduced at the free-trade equilibrium level of export is welfare-improving for the importing country if and only if the foreign exporter is forced to comply with the restraint involuntarily.

This paper analyzes voluntary export restraints in a dynamic setting where oligopolistic firms interact participating in a differential game. To

\footnotetext{
${ }^{1}$ Some of these exceptions are Cheng (1987), Driskill and McCafferty (1989a, 1996), Dockner and Haug (1990, 1991) and Calzolari and Lambertini (2001). Herguera, Kujal and Petrakis (2000) study the effects of quantity restrictions (such as VERs) on the long run choice of quality in a vertical product differentiation model with Cournot competition.

${ }^{2}$ See also Pomfret (1989) for a detailed survey on VERs.
} 
our knowledge, the only existing contribution in this vein is due to Dockner and Haug (1991), who analyse VERs in a dynamic oligopoly game with Cournot competition, adopting a sticky-price model of dynamic oligopoly. ${ }^{3}$ Restricting, for simplicity, the analysis to a speed of price adjustment which goes to infinity, they showed that indeed VER is voluntary as it increases profit of both domestic and foreign firms. However, this result stems from the fact that, since the price is the state variable, interaction among output levels takes place only through co-state equations, as each firm's first order condition w.r.t. own quantity is independent of the other firms'.

Instead, one could consider that capital accumulation is one of the most important strategic decision firms are confronted with. Hence, following the literature initiated by Spence (1979), we explicitly model firm's dynamic capital accumulation decisions and study the effects of a VER on firms' profits and equilibrium prices. To this end, we will study both the NerloveArrow (1962) model of reversible investment (i.e., accumulation with capital depreciation) and the Ramsey (1928) model (i.e., the well known "corn-corn" growth model).

When dealing with dynamic differential games, different strategies and solution concepts may be applied. The existing literature mainly concentrates on two kind of strategies: ${ }^{4}$ the open-loop and the closed-loop ones. In the former case, firms precommit to an investment path over the whole time horizon of the game, and the relevant equilibrium concept is the open-loop Nash equilibrium. In the latter, firms do not precommit on investment path and their strategies at any instant depend upon all the preceding history of the game, as described by the evolution of state variables and their influence upon the evolution of control variables.

Dockner and Haug (1991) restrict the analysis to the closed-loop nomemory (Markov Perfect) Nash equilibrium and, as in most of the literature, they have adopted a refinement of the closed-loop Nash equilibrium, which is known as the feedback Nash equilibrium. ${ }^{5}$ In the present paper, we will not restrict to this refinement and deal with both the open-loop and closed loop no-memory solutions. Under these two solution concepts, we will study whether a VER leads to more or less cooperative equilibria and then higher or smaller profits for firms, as compared to the free trade equilibrium.

We rely on a result which is proved by Cellini and Lambertini (2001), namely, that under both the Solow-Nerlove-Arrow and the Ramsey capi-

\footnotetext{
${ }^{3}$ This model is due to Simaan and Takayama (1978). It has been extended by Fershtman and Kamien (1987, 1990) and Tsutsui and Mino (1990).

${ }^{4}$ See Kamien and Schwartz (1981); Başar and Olsder (1982); Mehlmann (1988).

${ }^{5}$ For a clear exposition of the difference among these equilibrium solutions see Başar and Olsder (1982, pp. 318-327, and chapter 6, in particular Proposition 6.1).
} 
tal accumulation dynamics, the open-loop Nash equilibrium coincides with the closed-loop (no-memory) equilibrium (and therefore the open-loop one is subgame perfect).

We explicitly deal with the effects of VERs over profits and equilibrium quantities, using alternatively the two accumulation rules, and considering both Cournot and Bertrand competition.

The results emerging under Cournot competition are as follows. Under the Solow-Nerlove-Arrow accumulation, a free trade equivalent export restraint induces the same equilibrium price which would prevail with free trade and, as a consequence, firm's profits are unaffected. However, this does not hold if the VER further reduces imports with respect to the free trade level. In this case, since competition takes place à la Cournot, the firm reducing its production will be negatively affected and a VER cannot be observed at equilibrium. Under Ramsey capital accumulation, we show that any VER benefits the domestic firm but it hurts the foreign firm which imposes it. It follows that, again, a VER cannot be observed in equilibrium.

Under Bertrand competition, the two models exhibit largely different features. First of all, in the Solow-Nerlove-Arrow setting, price competition is observationally equivalent (in steady state) to quantity competition, in that firms choose exactly the same capacities in both cases. This means that the differential game with reversible investment in capacity encompasses the well known result of Kreps and Scheinkman (1983), who show in a static two-stage game that capacity-constrained price competition gives rise to a Cournot equilibrium. Second, this also entails that the adoption by the foreign firm of a VER equal to the free trade capacity doesn't change the picture at all, in that the steady state associated with free trade equivalent export restraint is qualitatively identical to the free trade equilibrium.

The Ramsey model behaves differently in that here the VER may increase the profits of both firms, as we are used to see in static models of price competition, and exactly for the same reason, namely, that a quantity commitment on the part of the foreign firm yields a quasi-Stackelberg price equilibrium, with the foreign firm in the follower's (respectively, leader's) position if products are substitutes (complements). The intuition behind the performance of the Ramsey model as compared to the Solow-Nerlove-Arrow model comes from the different nature of capital accumulation in the two models. While the Ramsey model is more elastic in that respect, as the current unsold output increases the stock of capital in the future, the SolowNerlove-Arrow model is more rigid in that capacity and sales coincide in each period, and therefore it is immaterial to firms whether market competition takes place in prices or output levels.

This allows us to draw the following implication, which extends to two well 
known dynamic settings a conclusion reached by most of the aforementioned static literature on this topic. As VERs are usually observed in several markets, and their adoption is not justified when firms set output levels, then the viability of VERs as coordinating or quasi-collusive instruments is confined to those cases where firms compete in prices and the decision on sales is not influenced by investment plans concerning capacity, i.e., the cases where firms define their respective price lists and then adjust production to the realization of demand levels.

The paper is organized as follows. The general setting is laid out in section 2. Section 3 is devoted to the analysis of Cournot competition under the two alternative capital accumulation rules. Bertrand behaviour in the two models is investigated in section 4 . Concluding remarks are in section 5 .

\section{The setup}

As in the previous literature on this topic, we consider a duopoly market supplied by a domestic producer (firm $D$ ) and a foreign rival (firm $F$ ).

The model is built in continuous time. The market exists over $t \in[0, \infty)$. Let $q_{i}(t)$ define the quantity sold by firm $i, i=D, F$, at time $t$. The marginal production cost is constant and equal across firms. For simplicity, we normalise it to zero. The inverse demand function of firm $i$ at time $t$ is:

$$
p_{i}(t)=a-q_{i}(t)-s q_{j}(t),
$$

with $i=D, F, i \neq j$. When $s \in(0,1)$, products are substitutes, while they are complements when $s \in(-1,0)$, and independent with $s=0$. The substitutability parameter $s \in(-1,1)$ ensures that quantities are never negative. ${ }^{6}$

In order to produce, firms must accumulate capacity or physical capital $k_{i}(t)$ over time. In the remainder of the paper, we will investigate two alternative models of capital accumulation:

A ] The Solow (1956) and Nerlove-Arrow (1962) model, where the relevant dynamic equation is:

$$
\frac{\partial k_{i}(t)}{\partial t}=I_{i}(t)-\delta k_{i}(t)
$$

\footnotetext{
${ }^{6}$ This formulation of market demand functions with product differentiation dates back to Bowley (1924) and is commonly used in the industrial organization literature since Dixit (1979) and Singh and Vives (1984).
} 
where $I_{i}(t)$ is the investment carried out by firm $i$ at time $t$, and $\delta$ is the constant depreciation rate. The instantaneous cost of investment is $C_{i}\left[I_{i}(t)\right]=b\left[I_{i}(t)\right]^{2}$, with $b>0$. To solve this model explicitly, we also assume that firms operate with a constant returns technology $q_{i}(t)=k_{i}(t)$, so that the demand function rewrites as: ${ }^{7}$

$$
p_{i}(t)=a-k_{i}(t)-s k_{j}(t) .
$$

Here, the control variable is the instantaneous investment $I_{i}(t)$, while the state variable is obviously $k_{i}(t)$.

B ] The Ramsey (1928) model, with the following dynamic equation:

$$
\frac{\partial k_{i}(t)}{\partial t}=f\left(k_{i}(t)\right)-q_{i}(t)-\delta k_{i}(t)
$$

where $f\left(k_{i}(t)\right)=y_{i}(t)$ denotes the output produced by firm $i$ at time $t$. In this case, capital accumulates as a result of intertemporal relocation of unsold output $y_{i}(t)-q_{i}(t)$. This can be interpreted in two ways. The first consists in viewing this setup as a corn-corn model, where unsold output is reintroduced in the production process. The second consists in thinking of a two-sector economy where there exists an industry producing the capital input which can be traded against the final good at a price equal to one (see Cellini and Lambertini, 1998, 2000).

In this model, the control variable is $q_{i}(t)$, while the state variable remains $k_{i}(t)$.

Concerning instantaneous variable costs, we assume that unit production cost is constant and equal across firms. For the sake of simplicity, and without further loss of generality, we also assume it to be nil.

Both in model [A] and in model [B], we address the issue whether an export restraint can be voluntarily adopted by firm $F$.

\section{Firms competing on quantities}

When firms compete à la Cournot, the relevant (inverse) demand functions are (1) under the Ramsey accumulation dynamics and (3) under the SolowNerlove-Arrow accumulation dynamics, respectively.

\footnotetext{
${ }^{7}$ Notice that this assumption entails that firms always operate at full capacity. This, in turn, amounts to saying that this model encompasses the case of Bertrand behaviour under capacity constraints, as in Kreps and Scheinkman (1983). The open-loop solution of the Nerlove-Arrow differential duopoly game in a model without trade is in Fershtman and Muller (1984) and Reynolds (1987).
} 


\subsection{The Solow-Nerlove-Arrow model}

In the Solow-Nerlove-Arrow model, the closed-loop formulation of the Hamiltonian of the domestic firm writes as follows:

$$
\begin{aligned}
\mathcal{H}_{D}(t)= & e^{-\rho t} \cdot\left\{\left[a-k_{D}(t)-s k_{F}(t)\right] k_{D}(t)-b\left[I_{D}(t)\right]^{2}+\right. \\
& \left.+\lambda_{D D}(t)\left[I_{D}(t)-\delta k_{D}(t)\right]+\lambda_{D F}(t)\left[I_{F}(t)-\delta k_{F}(t)\right]\right\}
\end{aligned}
$$

where $\lambda_{D i}(t)=\mu_{D i}(t) e^{\rho t}$, and $\mu_{D i}(t)$ is the co-state variable associated to $k_{i}(t), i=D, F$. Moreover, let $k_{i}(0) \equiv k_{i 0}$ define the initial condition for firm $i$.

The Hamiltonian of the foreign firm is:

$$
\begin{aligned}
\mathcal{H}_{F}(t)= & e^{-\rho t} \cdot\left\{\left[a-s k_{D}(t)-k_{F}(t)\right] k_{F}(t)-b\left[I_{F}(t)\right]^{2}+\right. \\
& \left.+\lambda_{F F}(t)\left[I_{F}(t)-\delta k_{F}(t)\right]+\lambda_{F D}(t)\left[I_{D}(t)-\delta k_{D}(t)\right]\right\}
\end{aligned}
$$

On the basis of (5) and (6), we can prove the following:

Proposition 1 Under the Solow-Nerlove-Arrow capital accumulation dynamics, the open-loop Nash equilibrium is a degenerate closed-loop memoryless equilibrium. Therefore, the open-loop equilibrium is subgame perfect.

Proof. See the appendix.

Accordingly, in the remainder we use the open-loop Hamiltonian:

$$
\mathcal{H}_{i}(t)=e^{-\rho t} \cdot\left\{\left[a-k_{i}(t)-s k_{j}(t)\right] k_{i}(t)-b\left[I_{i}(t)\right]^{2}+\lambda_{i}(t)\left[I_{i}(t)-\delta k_{i}(t)\right]\right\} .
$$

Firm $i$ 's first order conditions are (the transversality condition is omitted for brevity):

$$
\begin{gathered}
\frac{\partial \mathcal{H}_{i}(t)}{\partial I_{i}(t)}=0 \Rightarrow-2 b I_{i}(t)+\lambda_{i}(t)=0 \\
-\frac{\partial \mathcal{H}_{i}(t)}{\partial k_{i}(t)}=\frac{\partial \lambda_{i}(t)}{\partial t}-\rho \lambda_{i}(t) \Rightarrow \\
\frac{\partial \lambda_{i}(t)}{\partial t}=(\rho+\delta) \lambda_{i}(t)-\left[a-2 k_{i}(t)-s k_{j}(t)\right]
\end{gathered}
$$

Now we can explicitly look for steady state points under free trade. From the first order condition w.r.t. $I_{i}(t)$, we obtain:

$$
\frac{\partial I_{i}(t)}{\partial t}=\frac{1}{2 b} \frac{\partial \lambda_{i}(t)}{\partial t}=I_{i}(t)(\rho+\delta)-\frac{a-2 k_{i}(t)-s k_{j}(t)}{2 b}
$$


Now, solving the system:

$$
\frac{\partial I_{i}(t)}{\partial t}=0 ; \frac{\partial k_{i}(t)}{\partial t}=0, i=D, F
$$

we calculate the steady state levels of states and controls:

$$
I^{s s}=\frac{\delta a}{2+s+2 b(\rho+\delta) \delta} ; k^{s s}=\frac{I^{s s}}{\delta} .
$$

The pair $\left\{I^{s s}, k^{s s}\right\}$ is a saddle point. ${ }^{8}$

If an export restraint (equivalent to the free trade level of $k_{F}^{s s}$ ) is adopted by firm $F$, the domestic firm's optimization problem becomes

$\max _{I_{D}(t)} \mathcal{H}_{D}(t)=e^{-\rho t} \cdot\left\{\left[a-k_{D}(t)-s \bar{k}_{F}\right] k_{D}(t)-b\left[I_{D}(t)\right]^{2}+\lambda_{D}(t)\left[I_{D}(t)-\delta k_{D}(t)\right]\right\}$

where $\bar{k}_{F}=k_{F}^{s s}=\frac{I_{F}^{s s}}{\delta}$. It is immediate to verify that the first order conditions for the optimum of firm $D$ coincide with (8-9).

The above discussion proves the following result:

Proposition 2 Under the Solow-Nerlove-Arrow capital accumulation dynamics, with a free trade equivalent export restraint, the steady state equilibrium price in the domestic market is the same under both free trade and VER.

As a corollary, notice that both firms' steady state profits are also the same as under free trade. Essentially, the above result is driven by the fact that, in the Solow-Nerlove-Arrow model, there is no strategic interaction in the choice of optimal investment on the part of firms, i.e., firm $i$ 's first order condition on investment (8) only contain the own control, and not the rival's. Hence, the behaviour of firm $D$ is unaffected by an export restraint set by firm $F$ at the free trade level. Obviously, this does not hold if $\bar{k}_{F} \in\left(0, k_{F}^{s s}\right)$. To verify this, we can use (10) to obtain:

$$
I_{D}(t)=\frac{\delta\left[a-s \bar{k}_{F}\right]}{2[1+b(\rho+\delta) \delta]}
$$

and, correspondingly, $k_{D}(t)=I_{D}(t) / \delta$, with

$$
\frac{\partial I_{D}(t)}{\partial \bar{k}_{F}}<0 ; \frac{\partial k_{D}(t)}{\partial \bar{k}_{F}}<0,
$$

which shows that, since market competition takes place à la Cournot, any reduction in the capacity of firm $F$ entails an increase in the capacity of firm $D$. The same applies to profits. Therefore, we have the following:

\footnotetext{
${ }^{8}$ The proof is omitted for brevity. See Cellini and Lambertini (2001).
} 
Proposition 3 A voluntary export restraint cannot be observed at equilibrium in the Solow-Nerlove-Arrow model.

\subsection{The Ramsey model}

Under the capital accumulation rule (4), the closed-loop formulation of problem of firm $i$ is the following:

$$
\begin{aligned}
\mathcal{H}_{i}(t)= & e^{-\rho t}\left\{q_{i}(t)\left[a-q_{i}(t)-s q_{j}(t)\right]+\right. \\
& +\lambda_{i i}(t)\left[f\left(k_{i}(t)\right)-q_{i}(t)-\delta k_{i}(t)\right]+ \\
& \left.+\lambda_{i j}(t)\left[f\left(k_{j}(t)\right)-q_{j}(t)-\delta k_{j}(t)\right]\right\},
\end{aligned}
$$

where $\lambda_{i j}(t)=\mu_{i j}(t) e^{\rho t}$, and $\mu_{i j}(t)$ is the co-state variable associated by firm $i$ to state $k_{j}(t)$. As in the previous model, $k_{i}(0) \equiv k_{i 0}$ defines the initial condition for firm $i$.

We can prove the analogous to Proposition 1:

Proposition 4 Under the Ramsey capital accumulation dynamics, the openloop Nash equilibrium is subgame perfect.

Proof. See the appendix.

Now move on to the solution of the open-loop problem:

$$
\mathcal{H}_{i}(t)=e^{-\rho t}\left\{q_{i}(t)\left[a-q_{i}(t)-s q_{j}(t)\right]+\lambda_{i}(t)\left[f\left(k_{i}(t)\right)-q_{i}(t)-\delta k_{i}(t)\right]\right\} .
$$

From the first order condition on $q_{i}(t)$, we obtain the best reply function of firm $i$ :

$$
q_{i}^{b r}(t)=\frac{a-s q_{j}(t)-\lambda_{i}(t)}{2} .
$$

The co-state equation of firm $i$ writes as follows:

$$
-\frac{\partial \mathcal{H}_{i}(t)}{\partial k_{i}(t)}=\frac{\partial \mu_{i}(t)}{\partial t} \Rightarrow \frac{\partial \lambda_{i}(t)}{\partial t}=\left[\rho+\delta-f^{\prime}\left(k_{i}(t)\right)\right] \lambda_{i}(t)
$$

The best reply function (18) can be differentiated w.r.t. time to yield:

$$
\frac{d q_{i}(t)}{d t}=-\frac{s \cdot d q_{j}(t) / d t+d \lambda_{i}(t) / d t}{2} .
$$

Then, using

$$
\lambda_{i}(t)=a-2 q_{i}(t)-s q_{j}(t)
$$


and (19), we obtain:

$$
\frac{d q_{i}(t)}{d t}=\frac{s \cdot d q_{j}(t) / d t+\left[a-2 q_{i}(t)-s q_{j}(t)\right]\left[\rho+\delta-f^{\prime}\left(k_{i}(t)\right)\right]}{2}
$$

which, invoking symmetry, can be rearranged to yield:

$$
\frac{d q(t)}{d t}=\frac{[a-c-(2+s) q(t)]\left[\rho+\delta-f^{\prime}\left(k_{i}(t)\right)\right]}{2+s}
$$

Imposing $d q(t) / d t=0$ and solving, we obtain the following set of solutions:

$$
f^{\prime}(k(t))=\rho+\delta
$$

and

$$
q^{s s}=\frac{a}{2+s},
$$

where $q^{s s}$ is the solution driven by demand and cost conditions, while $f^{\prime}(k(t))=$ $\rho+\delta$ is the Ramsey equilibrium dictated by intertemporal capital accumulation alone.

The phase diagram illustrating the dynamics of the system is in figure 1, where the locus $\partial k / \partial t=0$ as well as the behaviour of $k$, depicted by horizontal arrows, derive from (4). Steady states are identified by the intersections between loci.

Figure 1: Steady state equilibrium under a tariff

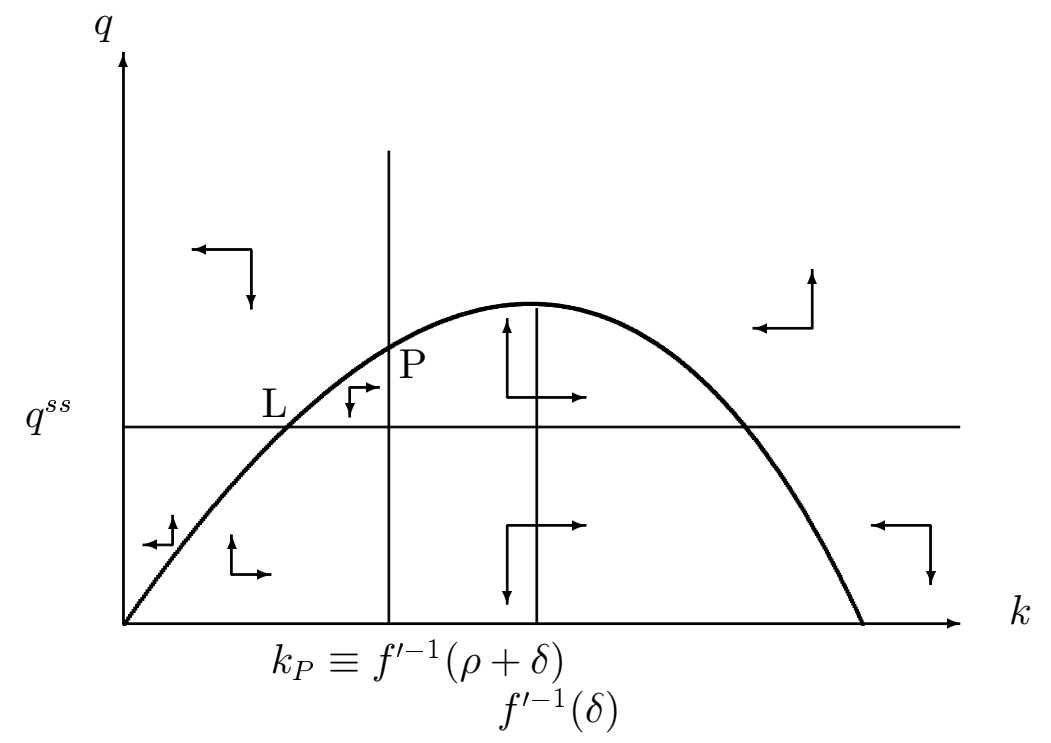


It is worth noting that the situation illustrated in figure 1 is only one out of several possible configurations, due to the fact that the position of the vertical line $f^{\prime}(k)=\rho+\delta$ is independent of demand parameters, while the horizontal loci $q^{s s}$ shifts upwards (downwards) as $a$ increases (decreases). Here, we confine to the case where the horizontal locus $q^{s s}$ intersects the locus $\partial k / \partial t=0$ in the region where the latter is increasing in $k$, to the left of the Ramsey equilibrium $f^{\prime}(k(t))=\rho+\delta$. Steady state points are identified as $L$ and $P$. Intersections to the right of $k=f^{\prime-1}(\delta)$ are clearly inefficient and therefore can be disregarded. Stability analysis reveals that $\{L, P\}$ are saddle points. ${ }^{9}$

The foregoing discussion can be summarised as follows:

Lemma 1 Under free trade, for all $\{a, c\}$ such that

$$
\frac{a}{2+s} \leq f\left(k_{P}\right)
$$

the system reaches a steady state at

$$
q^{s s}=\frac{a}{2+s},
$$

which is a saddle.

Now we shall take into consideration the alternative setting where firm $F$ adopts an export restraint $\bar{q}_{F}$ (which, for instance but not necessarily, can be fixed at the free trade level $q^{s s}$ ). The issue can be quickly dealt with by observing how the best reply of firm $D$ modifies in the presence of an export restraint. From (18), we can write:

$$
q_{D}^{b r}(t)=\frac{a-s \bar{q}_{F}-\lambda_{D}(t)}{2}
$$

where $\bar{q}_{F} \leq a / 3$. It is immediate to verify that

$$
\frac{d q_{D}(t)}{d t}=-\frac{d \lambda_{D}(t)}{d t}=-\left[\rho+\delta-f^{\prime}\left(k_{D}(t)\right)\right] \lambda_{D}(t),
$$

where, from $(25), \lambda_{D}(t)=a-2 q_{D}(t)-s \bar{q}_{F}$. This entails that the optimal quantity offered by the domestic firm in steady state depends on her initial condition $k_{D 0}$. While in the free trade setting the imposition of symmetry entails that both firms converge either to the demand-driven or to the Ramsey

\footnotetext{
${ }^{9}$ The stability analysis is omitted for the sake of brevity. See Cellini and Lambertini (1998) for details.
} 
equilibrium, here the adoption of a VER amounts to abandoning symmetry, with the domestic firm being in steady state at either $f^{\prime}\left(k_{D}(t)\right)=\rho+\delta$ or $q_{D}(t)=\left(a-s \bar{q}_{F}\right) / 2$ depending upon the level of $k_{D 0}$. An interesting limit case may arise, where $\bar{q}_{F}$ is sufficiently lower than $a / 3$ and consequently $q_{D}(t)$ becomes sufficiently large to coincide with the Ramsey equilibrium. This situation is illustrated in figure 2 (the horizontal and vertical arrows describing the dynamics of $\{k, q\}$ are omitted).

Figure 2: Steady state equilibrium under a VER

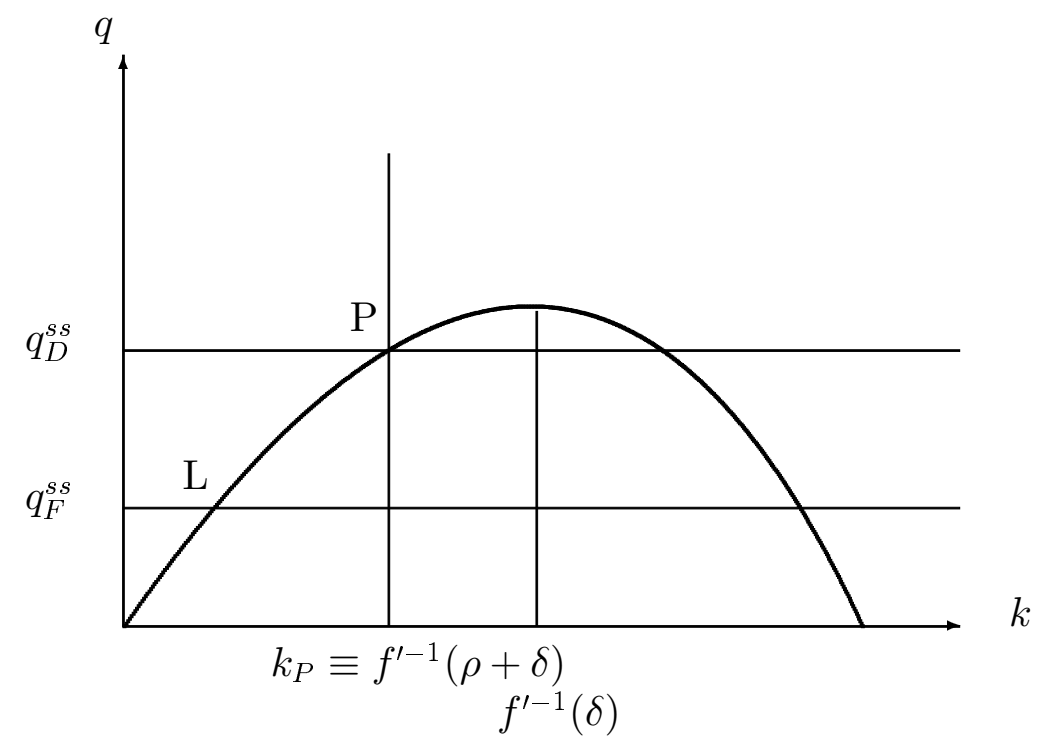

The foregoing discussion proves the following result:

Lemma 2 Under the Ramsey capital accumulation constraint, the adoption of any export restraint may drive the domestic firm either to the demanddriven equilibrium $q_{D}^{s s}(t)=\left(a-s \bar{q}_{F}\right) / 2$, or to the Ramsey equilibrium where $f^{\prime}\left(k_{D}(t)\right)=\rho+\delta$ and $q_{D}^{s s}=f\left(k_{P}\right)>\bar{q}_{F}$, depending on the initial condition $k_{D 0}$. In the first case, the export restraint benefits firm $d$ and hurts firm $F$ for all $\bar{q}_{F}<q^{s s}$. In the second case this holds for all $\bar{q}_{F} \leq q^{s s}$. Therefore, in general:

$$
\pi_{D}\left(\bar{q}_{F}\right) \geq \pi_{F}\left(\bar{q}_{F}\right) .
$$

Lemmata 1-2 produce the following result:

Proposition 5 A voluntary export restraint cannot be observed at equilibrium in the Ramsey model. 


\section{Firms competing on prices}

With price competition à la Bertrand, from (1) the demand function firm $i$ faces at time $t$ is

$$
q_{i}(t)=\frac{a}{1+s}-\frac{p_{i}(t)}{1-s^{2}}+\frac{s p_{j}(t)}{1-s^{2}}
$$

where $p_{i}(t)$ and $p_{j}(t)$ are respectively the price set by firms $i$ and $j$, respectively.

\subsection{The Solow-Nerlove-Arrow model}

Under the capital accumulation rule (2), and using the assumption $q_{i}(t)=$ $k_{i}(t)$, the closed-loop Hamiltonian of firm $i$ is:

$$
\begin{aligned}
\mathcal{H}_{i}(t)= & e^{-\rho t}\left\{\left[\frac{a}{1+s}-\frac{p_{i}(t)}{1-s^{2}}+\frac{s p_{j}(t)}{1-s^{2}}\right] p_{i}(t)+\right. \\
& \lambda_{i i}(t)\left[I_{i}(t)-\delta\left(\frac{a}{1+s}+\frac{p_{i}(t)}{1-s^{2}}-\frac{s p_{j}(t)}{1-s^{2}}\right)\right]+ \\
& \left.\lambda_{i j}(t)\left[I_{j}(t)-\delta\left(\frac{a}{1+s}+\frac{p_{j}(t)}{1-s^{2}}-\frac{s p_{i}(t)}{1-s^{2}}\right)\right]\right\}
\end{aligned}
$$

where $\lambda_{i j}(t)=\mu_{i j}(t) e^{\rho t}$, and $\mu_{i j}(t)$ is the co-state variable associated by firm $i$ to the state variable $k_{j}(t)$.

The equivalent of Proposition 1 is easy to prove. That is, first order conditions on controls do not contain the state variables, and therefore the open-loop equilibrium is subgame perfect. The details are omitted for brevity.

Accordingly, we proceed by solving the open-loop formulation of the game, which obtains from (28) by setting $\lambda_{i j}(t)=0$ and $\lambda_{i i}(t)=\lambda_{i}(t)$. The outcome is summarised by the following:

Proposition 6 The steady state of the Solow-Nerlove-Arrow game with Bertrand competition is observationally equivalent to the steady state of the same game with Cournot competition.

Proof. The first order condition on investment is:

$$
\frac{\partial \mathcal{H}_{i}(t)}{\partial I_{i}(t)}=0 \Rightarrow-2 b I_{i}(t)+\lambda_{i}(t)=0,
$$

yielding

$$
\begin{aligned}
\lambda_{i}(t) & =2 b I_{i}(t) \\
\frac{\partial I_{i}(t)}{\partial t} & =\frac{1}{2 b} \frac{\partial \lambda_{i}(t)}{\partial t}
\end{aligned}
$$


In the Bertrand setting, deriving the co-state equation is more involved that in the Cournot setting. Since we are using direct demand functions, capacity $k_{i}(t)$ is expressed as a function of the price vector $\left\{p_{i}(t), p_{j}(t)\right\}$. Therefore,

$$
\frac{\partial \mathcal{H}_{i}(t)}{\partial k_{i}(t)}=\frac{\partial \mathcal{H}_{i}(t)}{\partial p_{i}(t)} \frac{\partial p_{i}(t)}{\partial k_{i}(t)}+\frac{\partial \mathcal{H}_{i}(t)}{\partial p_{j}(t)} \frac{\partial p_{j}(t)}{\partial k_{i}(t)}
$$

where

$$
\begin{aligned}
\frac{\partial \mathcal{H}_{i}(t)}{\partial p_{i}(t)} & =\frac{a(1+s)-2 p_{i}(t)+s p_{j}(t)+\delta \lambda_{i}(t)}{1-s^{2}} ; \\
\frac{\partial \mathcal{H}_{i}(t)}{\partial p_{j}(t)} & =\frac{s\left[p_{i}(t)-\delta \lambda_{i}(t)\right]}{1-s^{2}} ; \\
\frac{\partial p_{i}(t)}{\partial k_{i}(t)} & =-1 ; \frac{\partial p_{j}(t)}{\partial k_{i}(t)}=-s .
\end{aligned}
$$

Using (33), the co-state equation writes as follows:

$$
\begin{gathered}
-\left[\frac{\partial \mathcal{H}_{i}(t)}{\partial p_{i}(t)} \frac{\partial p_{i}(t)}{\partial k_{i}(t)}+\frac{\partial \mathcal{H}_{i}(t)}{\partial p_{j}(t)} \frac{\partial p_{j}(t)}{\partial k_{i}(t)}\right]=\frac{\partial \lambda_{i}(t)}{\partial t}-\rho \lambda_{i}(t) \Rightarrow \\
\frac{\partial \lambda_{i}(t)}{\partial t}=\frac{a(1-s)-p_{i}(t)\left(2-s^{2}\right)+s p_{j}(t)+\lambda_{i}(t)(\rho+\delta)\left(1-s^{2}\right)}{1-s^{2}} .
\end{gathered}
$$

Then, plugging (30) and (35) into (31) and imposing the symmetry condition $p_{j}(t)=p_{i}(t)$, we obtain:

$$
\frac{\partial I_{i}(t)}{\partial t}=\frac{a-p_{i}(t)(2+s)+2 b I_{i}(t)(\rho+\delta)(1+s)}{2 b(1+s)}
$$

with

$$
\frac{\partial I_{i}(t)}{\partial t}=0 \text { at } I_{i}^{s s}=\frac{p_{i}(t)(2+s)-a}{2 b(\rho+\delta)(1+s)} .
$$

$I_{i}^{s s}$ can be substituted into (2), which simplifies as follows:

$$
\frac{\partial k_{i}(t)}{\partial t}=\frac{p_{i}(t)(2+s)-a}{2 b(\rho+\delta)(1+s)}-\frac{\delta\left[a-p_{i}(t)\right]}{1+s}
$$

with

$$
\frac{\partial k_{i}(t)}{\partial t}=0 \text { at } p_{i}^{s s}=\frac{a[1+2 b \delta(\rho+\delta)]}{2[1+b \delta(\rho+\delta)]+s}
$$

Now, using (39), we can simplify the expression for the steady state levels of investment and capacity:

$$
I_{i}^{s s}=\frac{\delta a}{2+s+2 b(\rho+\delta) \delta} ; k_{i}^{s s}=\frac{I_{i}^{s s}}{\delta},
$$


which coincide with (12). Also the equilibrium profits are obviously the same as in the Cournot game investigated in section 3.1.

The above result has the following intuitive explanation. The usual interpretation of the difference between Cournot and Bertrand in static games is that firms optimise w.r.t. either quantities or prices. However, in a differential game, using direct demand functions for the Bertrand case does not modify the strategy space for control variables, which are investment efforts. Therefore, in the Solow model, firms are not choosing prices or quantities and consequently the specific formulation of instantaneous profits is immaterial to the subgame perfect equilibrium emerging in steady state. Nevertheless, this conclusion was not obvious at the outset, in that inverting demand functions involves a reformulation of the dynamics of state variables as well as the co-state equations.

Proposition 7 has two relevant corollaries. The first is:

Corollary 1 In the Bertrand formulation of the Solow-Nerlove-Arrow game, the steady state price is the same as in the Cournot formulation of the game.

That is, when capital (or capacity) accumulates according to (2), the Bertrand paradox never arises. This is easily shown by verifying that $p_{i}^{s s}$ in (39) is always strictly higher than marginal cost $c$ for all admissible values of parameters. In particular, if $s=1$, then

$$
p_{i}^{s s}=\frac{a+2 a b \delta(\rho+\delta)}{3+2 b \delta(\rho+\delta)}
$$

which becomes

$$
p_{i}^{s s}=\frac{a}{3}
$$

when $\delta=0$. That is, when products are perfect substitutes and capital does not depreciate, the steady state price coincides with the well known equilibrium price associated with the static version of Cournot duopoly. The same obviously holds for capacity (and output), $k_{i}^{s s}=a / 3$. This entails that the Solow-Nerlove-Arrow model generalises the static two-stage game à la Kreps and Scheinkman (1983), where firms first choose capacities and then compete in prices. Indeed, the present model encompasses Kreps and Scheinkman's, with no need of resorting to mixed strategies, as it produces the Cournot equilibrium as the subgame perfect capacity-constrained equilibrium of a differential game in prices and investments in pure strategies.

The second corollary to Proposition 7 is: 
Corollary 2 Since the Bertrand equilibrium is observationally equivalent to the Cournot equilibrium, then (i) under a free trade equivalent export restraint, the domestic price is the same as under free trade, and (ii) a voluntary export restraint cannot be observed at equilibrium in the Solow-NerloveArrow model.

The proof of Corollary 2 is immediate, in that it relies on the information that Bertrand and Cournot competition are essentially the same if the capital accumulation dynamics is given by (2). An intuitive argument is the following. If the foreign firm adopts a capacity equal to the free trade level $k_{i}^{s s}$, then it is optimal for the domestic firm to reply by adopting the same capacity, and consequently the equilibrium under the VER cannot be distinguished from the free trade equilibrium. ${ }^{10}$

\subsection{The Ramsey model}

Under the capital accumulation rule (4), the problem of firm $i$ is the following:

$$
\begin{aligned}
\mathcal{H}_{i}(t)= & e^{-\rho t}\left\{\left[\frac{a}{1+s}-\frac{p_{i}(t)}{1-s^{2}}+\frac{s p_{j}(t)}{1-s^{2}}\right] p_{i}(t)+\right. \\
& \lambda_{i i}(t)\left[f\left(k_{i}(t)\right)+\frac{a}{1+s}+\frac{p_{i}(t)}{1-s^{2}}-\frac{s p_{j}(t)}{1-s^{2}}-\delta k_{i}(t)\right]+ \\
& \left.\lambda_{i j}(t)\left[f\left(k_{j}(t)\right)+\frac{a}{1+s}+\frac{p_{j}(t)}{1-s^{2}}-\frac{s p_{i}(t)}{1-s^{2}}-\delta k_{j}(t)\right]\right\},
\end{aligned}
$$

where $\lambda_{i j}(t)=\mu_{i j}(t) e^{\rho t}$, and $\mu_{i j}(t)$ is the co-state variable associated by firm $i$ to state $k_{j}(t)$.

Proceeding as with Proposition 4 one can simply show that the open-loop Nash equilibrium is subgame perfect also when firms compete on prices (the proof is omitted for brevity).

Moving on the solution of the open-loop problem, from the first order condition on $p_{i}(t)$, we obtain the best reply function of firm $i$ :

$$
p_{i}^{b r}(t)=\frac{a(1-s)+s p_{j}(t)+\lambda_{i}(t)}{2} .
$$

\footnotetext{
${ }^{10}$ Equivalently, one can reach the same conclusion by considering that firm $D$ must maximise the Hamiltonian of a firm that is a monopolist over a residual market demand function, given the free trade equivalent investment policy adopted by firm $F$. The details of the proof of Corollary 2 ara available upon request.
} 
Function (44) can be differentiated w.r.t. time to yield:

$$
\frac{d p_{i}(t)}{d t}=\frac{1}{2}\left[\frac{d p_{j}(t)}{d t} s+\frac{d \lambda_{i}(t)}{d t}\right]
$$

Then, using

$$
\lambda_{i}(t)=2 p_{i}(t)-a(1-s)-s p_{j}(t),
$$

and the co-state equation of firm $i$ which writes as in (19), we obtain:

$$
\frac{d p_{i}(t)}{d t}=\frac{1}{2}\left\{\frac{d p_{j}(t)}{d t} s+\left[2 p_{i}(t)-a(1-s)-s p_{j}(t)\right]\left[\rho+\delta-f^{\prime}\left(k_{i}(t)\right)\right]\right\}
$$

Invoking symmetry, this can be rearranged to yield:

$$
\frac{d p(t)}{d t}=\frac{1}{2-s}[(2-s) p(t)-a(1-s)]\left[\rho+\delta-f^{\prime}(k(t))\right]
$$

Imposing $d p(t) / d t=0$ and solving, we obtain the Ramsey equilibrium:

$$
f^{\prime}(k(t))=\rho+\delta
$$

and, substituting $p=a(1-s) /(2-s)$ into (1), the solution driven by demand and cost conditions:

$$
q^{s s}=\frac{a}{(1+s)(2-s)}
$$

The phase diagram illustrating the dynamics of the system is as in figure 1, and Lemma 1 applies qualitatively unmodified, although of course Bertrand behaviour entails a larger output and a lower price in steady state, as compared to Cournot, for all positive $s$ (and conversely).

With free trade and (49) applies, the instantaneous profit each firm obtains then is

$$
\Pi^{s s}=\frac{a^{2}(1-s)}{(2-s)^{2}(1+s)} .
$$

Now let us turn to the case where firm $F$ adopts an export restraint $\bar{q}_{F}$ equal to the free trade level $q^{s s}$.

Replace $q_{F}=q^{s s}$ into the inverse demand for firm $F$ and substitute back into the Hamiltonian of firm $D$. The best reply function of firm $D$ now becomes

$$
p_{D}^{b r}(t)=\frac{a\left(2-s^{2}\right)+(1+s)(2-s) \lambda_{D}(t)}{2(1+s)(2-s)} .
$$

Differentiating this best reply w.r.t. time yields:

$$
\frac{d p_{D}(t)}{d t}=\frac{1}{2} \frac{d \lambda_{D}(t)}{d t}
$$


Then, using

$$
\lambda_{D}(t)=2 p_{D}(t)-\frac{a\left(2-s^{2}\right)}{(1+s)(2-s)}
$$

and (19), we obtain:

$\frac{d p_{D}(t)}{d t}=\frac{1}{(1+s)(2-s)}\left[2 p_{D}(t)(1+s)(2-s)-a\left(2-s^{2}\right)\right]\left[\rho+\delta-f^{\prime}\left(k_{D}(t)\right)\right]$

Imposing $d p_{D}(t) / d t=0$ and solving, we obtain the Ramsey and the "market-driven" equilibria:

$$
\begin{aligned}
& f^{\prime}\left(k_{D}^{V E R}(t)\right)=\rho+\delta \\
& q_{D}^{V E R}=\frac{a\left(2-s^{2}\right)}{2(1+s)(2-s)} .
\end{aligned}
$$

On this basis, we can prove the following:

Proposition 7 Under the Ramsey capital accumulation regime,

1. the adoption of free trade-equivalent export restraint by firm $F$ benefits both firms as long as the steady state is driven by demand conditions only, i.e.,

$$
q_{F}=q^{s s}<q_{D}^{V E R} \leq f\left(k_{D}^{V E R}\right) .
$$

Firm $F$ benefits more (less) than firm $D$ if products are substitutes (complement).

2. If instead

$$
q_{F}=q^{s s}<f\left(k_{D}^{V E R}\right)<q_{D}^{V E R},
$$

the steady state profits of firm $F$ under the VER are lower than under free trade, and therefore the VER cannot be part of a subgame perfect equilibrium.

Proof. To prove the first part of the Proposition, we have to compare the profits firms $F$ and $D$ obtain when they respectively use the free trade VER $q_{F}=q^{s s}$ and the implied "market-driven" equilibrium quantity $q_{D}^{V E R}$, against the profits they obtain with no quantity restrictions adopted by firm $F$.

Calculating firm $F$ 's profit with VER

$$
\Pi_{F}^{V E R}=\frac{a^{2}\left[2-s^{2}(2-s)\right]}{2(1+s)^{2}(2-s)^{2}},
$$


the comparison of instantaneous profits for firm $F$ reveals that

$$
\Pi_{F}^{V E R}-\Pi^{s s}=\frac{a^{2} s^{3}}{2(1+s)^{2}(2-s)^{2}}>0 .
$$

Similarly, for firm $D$, we have

$$
\Pi_{D}^{V E R}=\left[\frac{a\left(2-d^{2}\right)}{2(1+d)(2-d)}\right]^{2} .
$$

and then

$$
\Pi_{D}^{V E R}-\Pi^{s s}=\frac{a^{2} s^{4}}{4(1+s)^{2}(2-s)^{2}}>0 .
$$

Moreover, we also obtain that

$$
\Pi_{F}^{V E R}-\Pi_{D}^{V E R}=\frac{a^{2} s^{3}}{4(1+s)^{2}(2-s)}
$$

and then

$$
\Pi_{F}^{V E R} \gtreqless \Pi_{D}^{V E R} \Leftrightarrow s \gtreqless 0 .
$$

This discussion proves item 1of the Proposition. Now we proceed with item 2, considering the situation where the best reply of firm $D$ to the VER is larger than the output associated with the Ramsey equilibrium dictated by intertemporal parameters and the marginal productivity of capital.

A necessary condition for the VER to be adopted is that

$$
\begin{aligned}
\Pi^{s s} & \leq \Pi_{F}^{V E R} \Leftrightarrow \\
\frac{a^{2}(1-s)}{(2-s)^{2}(1+s)} & \leq \frac{a}{(1+s)(2-s)}\left[a-\frac{a}{(1+s)(2-s)}-f\left(k_{D}^{V E R}\right)\right]
\end{aligned}
$$

which is satisfied iff

$$
f\left(k_{D}^{V E R}\right) \leq \frac{a s}{1+s}
$$

However, $f\left(k_{D}^{V E R}\right) \in\left(q^{s s}, q_{D}^{V E R}\right)$. Now it is easy to check that

$$
\frac{a s}{1+s}<q^{s s}
$$

which implies that the necessary condition is never met.

This Proposition shows that when firms compete on prices, then VERs may indeed be voluntary and serve as coordinating or quasi-collusive instruments. Ceteris paribus, this depends on the slope of technology. To 
see this, consider as given the set of demand and intertemporal parameters $\{a, s, \delta, \rho\}$. If so, the capital level associated with the Ramsey equilibrium increases as $f^{\prime}(k)$ increases. Accordingly, the same holds for the corresponding output level $f\left(k_{D}^{V E R}\right)$. Hence, the production possibility set wherein the VER is adopted in equilibrium because it is profitable for firm $F$ is directly related to the marginal productivity of capital. This phenomenon is illustrated in figure 3, where we consider a technical progress increasing the marginal productivity of capital from $f_{0}^{\prime}(k)$ to $f_{1}^{\prime}(k)$.

Figure 3 : The effect of a change in the productivity of capital

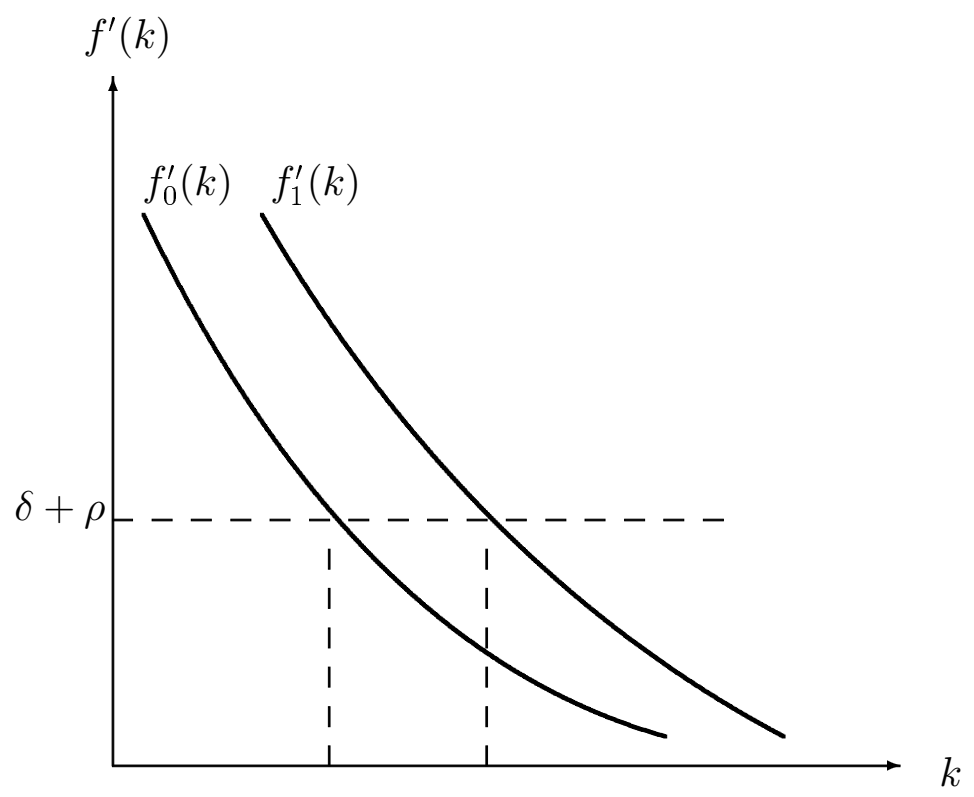

\section{Conclusions}

In this paper, we have analyzed the effects of voluntary export restraint in a continuous time differential game. We have explicitly introduced the firms' accumulation dynamics and showed that, in two well known accumulation models, open-loop and closed-loop (no-memory) Nash equilibria always coincide, irrespective of whether firms are price or quantity setters.

In the Cournot games, the main results are as follows. Under the SolowNerlove-Arrow (1962) accumulation dynamics, a free trade equivalent VER 
does not affect profits and the equilibrium price. However, any VER restricting quantity with respect to free trade hurts the firm employing this policy. The same holds, for any VER, under the Ramsey (1928) accumulation dynamics. Hence, contrary to the conclusions reached by Dockner and Haug (1991), VERs are not 'voluntarily' employed by Cournot firms. Therefore, the above analysis suggests that the empirical observation of VERs corresponds to their use as either coordinating or quasi-collusive devices in markets where firms are price setters and the sales decision is not constrained by capacity. This is confirmed by the analysis of price competition in the two models. Indeed, the Bertrand steady state of the Solow-Nerlove-Arrow model coincides with the Cournot equilibrium, and therefore the foreign firm cannot be expected to voluntarily adopt an export restraint. The opposite holds in the case of price behaviour in the Ramsey setting, where the adoption of an export restraint increases the profits of the foreign firm, provided that the market-driven equilibrium prevails. If instead the domestic firm is at the Ramsey equilibrium, the VER will not be adopted by the foreign rival. 


\section{Appendix}

Proof of Proposition 1. Necessary conditions for the domestic firm require:

$$
\begin{aligned}
& \text { (i) } \frac{\partial \mathcal{H}_{D}(t)}{\partial I_{D}(t)}=0 \Rightarrow-2 b I_{D}(t)+\lambda_{D D}(t)=0 \\
& (i i)-\frac{\partial \mathcal{H}_{D}(t)}{\partial k_{D}(t)}-\frac{\partial \mathcal{H}_{D}(t)}{\partial I_{F}(t)} \frac{\partial I_{F}(t)}{\partial k_{D}(t)}=\frac{\partial \lambda_{D D}(t)}{\partial t}-\rho \lambda_{D D}(t) \Rightarrow \\
& \Rightarrow-\frac{\partial \lambda_{D D}(t)}{\partial t}+\rho \lambda_{D D}(t)=a-2 k_{D}(t)-s k_{F}(t)-\delta \lambda_{D D}(t) \\
& (i i i)-\frac{\partial \mathcal{H}_{D}(t)}{\partial k_{F}(t)}-\frac{\partial \mathcal{H}_{D}(t)}{\partial I_{F}(t)} \frac{\partial I_{F}(t)}{\partial k_{F}(t)}=\frac{\partial \lambda_{D F}(t)}{\partial t}-\rho \lambda_{D F}(t) \\
& \text { (iv) } \lim _{t \rightarrow \infty} \mu_{D D}(t) \cdot k_{D}(t)=0 ; \lim _{t \rightarrow \infty} \mu_{D F}(t) \cdot k_{F}(t)=0,
\end{aligned}
$$

where $(i v)$ is the transversality condition.

Similarly for the foreign firm

$$
\begin{aligned}
& \text { (i) } \frac{\partial \mathcal{H}_{F}(t)}{\partial I_{F}(t)}=0 \Rightarrow-2 b I_{F}(t)+\lambda_{F F}(t)=0 \\
& (i i)-\frac{\partial \mathcal{H}_{F}(t)}{\partial k_{F}(t)}-\frac{\partial \mathcal{H}_{F}(t)}{\partial I_{D}(t)} \frac{\partial I_{D}(t)}{\partial k_{F}(t)}=\frac{\partial \lambda_{F F}(t)}{\partial t}-\rho \lambda_{F F}(t) \Rightarrow \\
& \Rightarrow-\frac{\partial \lambda_{F F}(t)}{\partial t}+\rho \lambda_{F F}(t)=a-2 k_{F}(t)-s k_{D}(t)-\delta \lambda_{F F}(t)-\tau \\
& (i i i)-\frac{\partial \mathcal{H}_{F}(t)}{\partial k_{D}(t)}-\frac{\partial \mathcal{H}_{F}(t)}{\partial I_{D}(t)} \frac{\partial I_{D}(t)}{\partial k_{D}(t)}=\frac{\partial \lambda_{F D}(t)}{\partial t}-\rho \lambda_{F D}(t) \\
& \text { (iv) } \lim _{t \rightarrow \infty} \mu_{F F}(t) \cdot k_{F}(t)=0 ; \lim _{t \rightarrow \infty} \mu_{F D}(t) \cdot k_{D}(t)=0,
\end{aligned}
$$

Notice that by (65.i) we have $\frac{\partial I_{i}(t)}{\partial k_{j}(t)}=0$ for $i$ different from $j$. Moreover, condition (65.iii), which yields $\partial \lambda_{D F}(t) / \partial t$, is redundant in that $\lambda_{D F}(t)$ does not appear in the first order conditions (65.i) and (65.ii). Therefore, the open-loop solution is indeed a degenerate closed-loop solution. ${ }^{11}$

Replace (65.i) into (65.ii) obtaining

$$
\frac{\partial \lambda_{D D}(t)}{\partial t}=b I_{D}(t)(\rho+\delta)-\left[a-2 k_{D}(t)-s k_{F}(t)\right]
$$

\footnotetext{
${ }^{11}$ Note that, however, the open-loop solution does not coincide with the feedback solution (see Reynolds, 1987). For further details, see Cellini and Lambertini (2001), as well as the discussion in Driskill and McCafferty (1989b, pp. 326-8). Classes of games where this coincidence arises are illustrated in Clemhout and Wan (1974); Reinganum (1982); Mehlmann and Willing (1983); Dockner, Feichtinger and Jørgensen (1985); Fershtman (1987). For an overview, see Mehlmann (1988); Fershtman, Kamien and Muller (1992).
} 
Then, differentiating (65.i) w.r.t. time and substituting the previous condition we obtain

$$
\frac{\partial I_{D}(t)}{\partial t}=\frac{I_{D}(t)(\rho+\delta)}{2}-\frac{a-2 k_{D}(t)-s k_{F}(t)}{2 b} .
$$

Similarly, condition (66.iii) yields $\partial \lambda_{F D}(t) / \partial t$, is redundant. This completes the proof.

Proof of Proposition 4. Firm i's first order condition concerning the control variable is:

$$
\frac{\partial \mathcal{H}_{i}(t)}{\partial q_{i}(t)}=a-2 q_{i}(t)-s q_{j}(t)-\lambda_{i i}(t)=0
$$

Now look at the co-state equation of firm $i$, for the closed-loop solution of the game:

$$
-\frac{\partial \mathcal{H}_{i}(t)}{\partial k_{i}(t)}-\frac{\partial \mathcal{H}_{i}(t)}{\partial q_{j}(t)} \frac{\partial q_{j}(t)}{\partial k_{i}(t)}=\frac{\partial \mu_{i i}(t)}{\partial t}
$$

where

$$
\frac{\partial q_{j}(t)}{\partial k_{i}(t)}=0
$$

as it appears from a quick inspection of best replies obtained from (68):

$$
q_{i}^{b r}(t)=\frac{a-s q_{j}(t)-\lambda_{i i}(t)}{2}
$$

Moreover, (71) suffices to establish that the co-state equation:

$$
-\frac{\partial \mathcal{H}_{i}(t)}{\partial k_{j}(t)}-\frac{\partial \mathcal{H}_{i}(t)}{\partial q_{j}(t)} \frac{\partial q_{j}(t)}{\partial k_{j}(t)}=\frac{\partial \mu_{i j}(t)}{\partial t}
$$

is indeed redundant since $\mu_{i j}(t)=\lambda_{i j}(t) e^{-\rho t}$ does not appear in the first order condition on the control variable. That is, the Ramsey game yields that the open-loop solution is a degenerate closed-loop solution because the best reply function of firm $i$ does not contain the state variable pertaining to the same firm. This concludes the proof. 


\section{References}

[1] Berry, S. J. Levinsohn and A. Pakes (1999), "Voluntary Export Restraints on Automobiles: Evaluating a Trade Policy", American Economic Review, 89, 400-30.

[2] Bowley, A.L. (1924), The Mathematical Groundwork of Economics, Oxford, Oxford University Press.

[3] Brander, J. (1995) "Strategic Trade Policy", in Grossman, G.M. and K. Rogoff (eds.), Handbook of International Economics, vol. 3, Amsterdam, North-Holland.

[4] Calzolari, G. and L. Lambertini (2001), "Tariffs vs Quotas in a Model of Trade with Capital Accumulation", in R. Neck (ed.), Proceedings of the IFAC Symposium on Modelling and Control of Economic Systems (SME 2001), Pergamon Press, forthcoming.

[5] Cellini, R. and L. Lambertini (1998), "A Dynamic Model of Differentiated Oligopoly with Capital Accumulation", Journal of Economic Theory, $\mathbf{8 3}, 145-55$.

[6] Cellini, R. and L. Lambertini (2000), "Non-Linear Market Demand and Capital Accumulation in a Differential Oligopoly Game", working paper no. 370, Dipartimento di Scienze Economiche, Università degli Studi di Bologna.

[7] Cellini, R. and L. Lambertini (2001), "Differential Oligopoly Games where the Closed-Loop Memoryless and Open-Loop Equilibria Coincide", mimeo, Dipartimento di Scienze Economiche, Università degli Studi di Bologna.

[8] Cheng, L. (1987), "Optimal Trade and Technology Policies: Dynamic Linkages", International Economic Review, 28, 757-76.

[9] Clemhout, S. and H.Y. Wan, Jr. (1974), "A Class of Trilinear Differential Games", Journal of Optimization Theory and Applications, 14, 419-24.

[10] Dixit, A.K. (1979), "A Model of Duopoly Suggesting a Theory of Entry Barriers", Bell Journal of Economics, 10, 20-32.

[11] Dockner, E.J. and A.A. Haug (1990), "Tariffs and Quotas under Dynamic Duopolistic Competition", Journal of International Economics, 29, 147-59. 
[12] Dockner, E.J. and A.A. Haug (1991), "The Closed Loop Motive for Voluntary Export Restraints", Canadian Journal of Economics, 3, 67985.

[13] Dockner, E.J., G. Feichtinger and S. Jørgensen (1985), "Tractable Classes of Nonzero-Sum Open-Loop Nash Differential Games: Theory and Examples", Journal of Optimization Theory and Applications, 45, 179-97.

[14] Dockner, E.J, S. Jørgensen, N. Van Long and G. Sorger (2000), Differential Games in Economics and Management Science, Cambridge, Cambridge University Press.

[15] Driskill, R. and S. McCafferty (1989a), "Dynamic Duopoly with Output Adjustment Costs in International Markets: Taking the Conjecture out of Conjectural Variations", in Feenstra, R.C. (ed.), Trade Policies for International Competitiveness, NBER Conference Report series, Chicago, University of Chicago Press, 125-37.

[16] Driskill, R. and S. McCafferty (1989b), "Dynamic Duopoly with Adjustment Costs: A Differential Game Approach", Journal of Economic Theory, 69, 324-38.

[17] Driskill, R. and S. McCafferty (1996), "Industrial Policy and Duopolistic Trade with Dynamic Demand", Review of Industrial Organization, 11, 355-73.

[18] Fershtman, C. (1987), "Identification of Classes of Differential Games for Which the Open-Loop is a degenertaed Feedback Nash Equilibrium", Journal of Optimization Theory and Applications, 55, 217-31.

[19] Fershtman, C. and M.I. Kamien (1987), "Dynamic Duopolistic Competition with Sticky Prices", Econometrica, 55, 1151-64.

[20] Fershtman, C. and M.I. Kamien (1990), "Turnpike Properties in a Finite-Horizon Differential Game: Dynamic Duopoly with Sticky Prices", International Economic Review, 31, 49-60.

[21] Fershtman, C. and E. Muller (1984), "Capital Accumulation Games of Infinite Duration", Journal of Economic Theory, 33, 322-39.

[22] Fershtman, C., M. Kamien and E. Muller (1992), "Integral Games: Theory and Applications", in Feichtinger, G. (ed.), Dynamic Economic Models and Optimal Control, Amsterdam, North-Holland, 297-311. 
[23] Harris, R. (1985), "Why Voluntary Export Restraints Are 'Voluntary", Canadian Journal of Economics, 18, 799-809.

[24] Herguera, I., P. Kujal and E. Petrakis (2000), "Quantity Restrictions and Endogenous Quality Choice", International Journal of Industrial Organization, 18, 1259-78.

[25] Hwang, H. and C. Mai (1988), "Why Voluntary Export Restraints Are Voluntary: An Extension", Canadian Journal of Economics, 21, 877-82.

[26] Kamien, M.I. and N.L. Schwartz (1981), Dynamic Optimization: The Calculus of Variations and Optimal Control in Economics and Management, Amsterdam, North-Holland.

[27] Kreps, D. and J. Scheinkman (1983), "Quantity Precommitment and Bertrand Competition Yield Cournot Outcomes", Bell Journal of Economics, 14, 326-37.

[28] Krishna, K. (1989), "Trade Restrictions as Facilitating Practices", Journal of International Economics, 26, 251-70.

[29] Mehlmann, A. (1988), Applied Differential Games, New York, Plenum Press.

[30] Mehlmann, A. and R. Willing (1983), "On Nonunique Closed-Loop Nash Equilibria for a Class of Differential Games with a Unique and Degenerate Feedback Solution", Journal of Optimization Theory and Applications, 41, 463-72.

[31] Nerlove, M. and K.J. Arrow (1962), "Optimal Advertising Policy under Dynamic Conditions", Economica, 29, 129-42.

[32] Pomfret, R. (1989), "The Economics of Voluntary Export Restraints Agreements", Journal of Economic Surveys, 3, 199-211.

[33] Ramsey, F.P. (1928), "A Mathematical Theory of Saving", Economic Journal, 38, 543-59. Reprinted in Stiglitz, J.E. and H. Uzawa (1969, eds.), Readings in the Modern Theory of Economic Growth, Cambridge, MA, MIT Press.

[34] Reinganum, J. (1982), "A Class of Differential Games for Which the Closed Loop and Open Loop Nash Equilibria Coincide", Journal of Optimization Theory and Applications, 36, 253-62. 
[35] Reynolds, S.S. (1987), "Capacity Investment, Preemption and Commitment in an Infinite Horizon Model", International Economic Review, 28, 69-88.

[36] Simaan, M. and T. Takayama (1978), "Game Theory Applied to Dynamic Duopoly Problems with Production Constraints", Automatica, 14, 161-66.

[37] Singh, N. and X. Vives (1984), "Price and Quantity Competition in a Differentiated Duopoly", RAND Journal of Economics, 15, 546-54.

[38] Solow, R. (1956), "A Contribution to the Theory of Economic Growth", Quarterly Journal of Economics, 70, 65-94.

[39] Spence, A. M. (1979), "Investment Strategy and Growth in a New Market", Bell Journal of Economics, 10, 1-19.

[40] Suzumura, K. and J. Ishikawa (1997), "Voluntary Export Restraints and Economic Welfare", Japanese Economic Review, 48, 176-86.

[41] Tsutsui, S. and K. Mino (1990), "Nonlinear Strategies in Dynamic Duopolistic Competition with Sticky Prices", Journal of Economic Theory, 52, 136-61. 